\title{
LITERATURE REVIEW: SENSITIVITY AND SPECIFICITY OF VDRL AND RPR AS SCREENING TESTS OF SYPHILIS IN PREGNANT WOMEN
}

\section{Tamara Audrey Kadarusman ${ }^{1}$, Sacharissa Zerlina Tsarwah Thirafi ${ }^{1}$, Niki Kusuma Bangsa $^{1}$, Rufina Adelia Widyatama ${ }^{1}$, Lutfi Dewanda Nugroho ${ }^{1}$, Prima Ardiansah Surya $^{1}$, Pudji Lestari*2 ${ }^{2}$}

${ }^{1}$ Faculty of Medicine, Universitas Airlangga, Indonesia, ${ }^{2}$ Department of Public Health-Preventive Medicine, Faculty of Medicine, Universitas Airlangga, Indonesia

\begin{abstract}
Early detection of syphilis, especially during pregnancy, is important to prevent comorbidities for the mother and the baby. This study aims to determine whether VDRL is more sensitive and specific than RPR as a diagnostic screening test for syphilis infection in pregnant women. Literature searches for relevant articles were conducted in PubMed, Cochrane, and Proquest using the keywords "VDRL AND RPR AND pregnancy AND syphilis". From the search results, we found 7 articles in Pubmed, 2.290 articles in Proquest, and no relevant articles were found in Cochrane. Title and abstracts were screened for their conformity with the case and clinical questions that had been made. Selected articles were then critically appraised. The results of the study in selected articles indicated that VDRL and RPR showed a false positives rate of $10.5 \%$ and $9.6 \%$, respectively. The sensitivity and specificity of VDRL were $71.6 \%$ and $89.5 \%$, and those of RPR were $73.5 \%$ and $90.5 \%$. VDRL and RPR have a moderate agreement with the TPHA (kappa $=0.6)$. From these studies it can be concluded that VDRL is not more sensitive and specific than $R P R$, implying that RPR is a better diagnostic screening test for syphilis infection in pregnant women than VDRL.
\end{abstract}

\author{
ARTICLE HISTORY \\ Received: May 28, 2020 \\ Revised: June 16, 2021 \\ Accepted: August 9, 2021 \\ Published: October 31, 2021 \\ (Online) \\ doi: \\ 10.20473/jcmphr.v2i2.26334
}

\section{KEYWORDS}

Evidence-Based Case Report, VDRL, RPR, syphilis, screening, communicable disease, maternal health

\section{CORRESPONDING}

AUTHOR

Pudji Lestari

$\triangle$ pulesaja@gmail.com

Department of Public HealthPreventive Medicine, Faculty of Medicine, Universitas Airlangga, Jl. Mayjend Prof. Dr. Moestopo 6-8, Surabaya, Indonesia

\section{INTRODUCTION}

In early adolescence (12-15 years), one's body undergoes changes accompanied by the development of 'new thoughts', so that they are easily attracted to the opposite sex and easily aroused. Adolescents with limited reproductive health knowledge are at higher risk of teenage pregnancy and sexually transmitted diseases such as syphilis because knowledge is associated with self-protection behavior. ${ }^{1}$ Inadequate treatment of syphilis could lead to health problems later in life.
Therefore, early detection of syphilis, especially during pregnancy, is important so as not to cause comorbidities for mother and baby. $^{2}$

For a very long time, RPR has been a standard diagnostic screening test for syphilis infection of pregnancy in Indonesia. This study aims to determine whether VDRL, which is a standard diagnostic screening test in other countries, is more sensitive and specific than RPR as a diagnostic screening test for syphilis infection in pregnant women. 
The RPR test uses the same antigen as VDRL, but the antigen is bound to a particle made of carbon, to make better visualization of the reaction without a microscope. RPR titers are usually known to be higher than the VDRL titers. ${ }^{3}$

The method of this study is literature review, in which literature searches for relevant articles were conducted in PubMed, Cochrane, and Proquest using the keywords "VDRL AND RPR AND pregnancy AND syphilis". From the search results, we found 7 articles in Pubmed, 2,290 articles in
Proquest, and no relevant articles were found in Cochrane. Title and abstracts were screened for their conformity with the case and clinical questions that had been made. The inclusion criteria were original research published in the last 12 months. Sources from worksheets, books, and wire feeds were excluded. Initial studies were screened again for full-text availability and their conformity to the research question, resulting in one study in the final analysis. The study was then critically appraised.

\section{OVERVIEW}

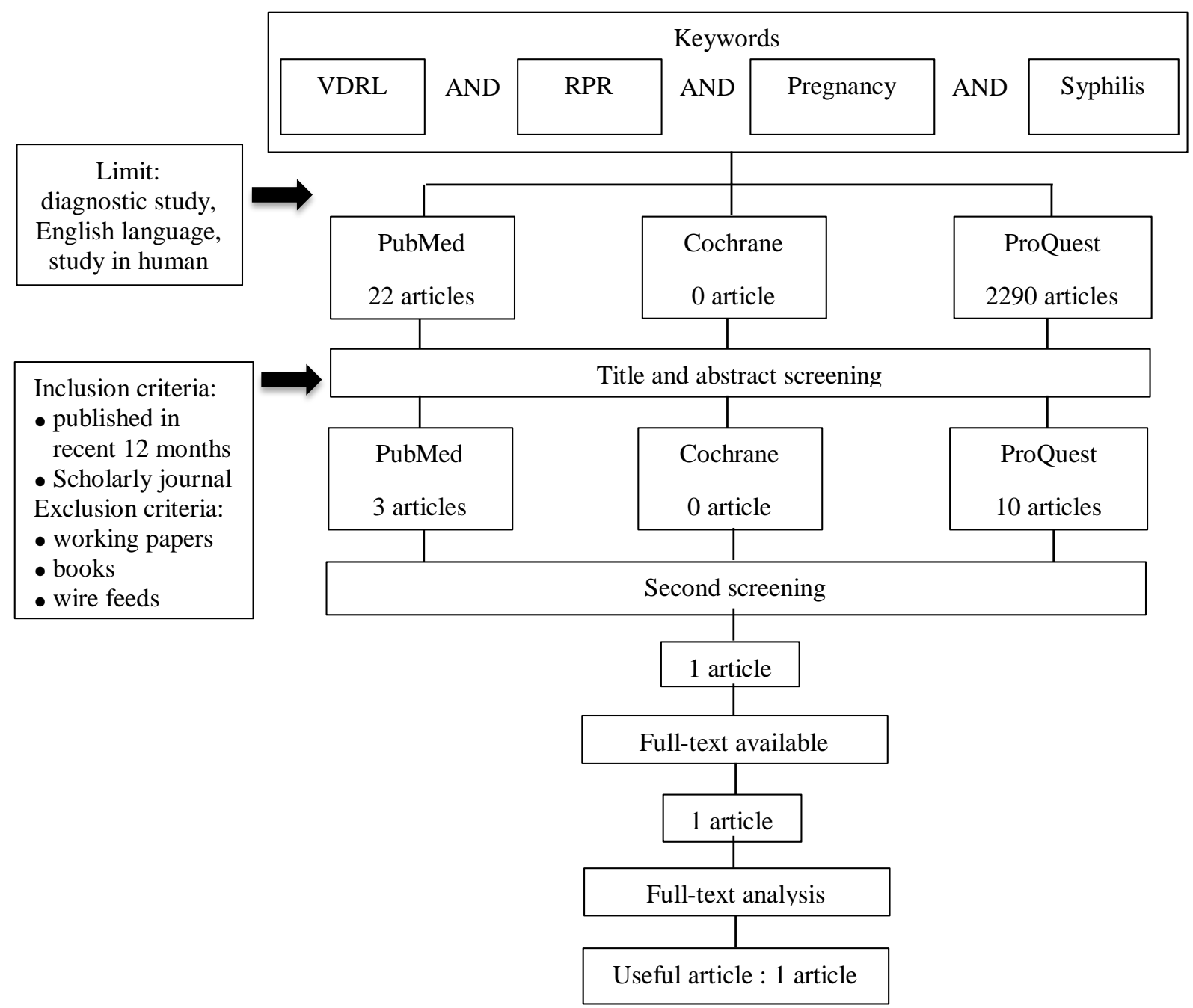

Figure 1. Workflow of article selection 
According to a study conducted by Solaimalai et al. (2020), untreated syphilis in pregnant women could lead to serious complications such as spontaneous abortion, stillbirth, perinatal death, and IUGR with congenital syphilis sequelae. ${ }^{4}$ In 2009 , the United States of Preventive Services Task Force (USPSTF) recommended mandatory screening for early syphilis because syphilis therapy with antibiotics in pregnancy is quite effective. ${ }^{5}$ Therefore, screening for syphilis is mandatory in early pregnancy or at the first antenatal visit as recommended by WHO (2017). ${ }^{6}$ In this study, RPR showed better results as a diagnostic screening test compared to VDRL ( $73.3 \%$ vs $71.6 \%$ ). This is supported by a higher specificity value in RPR (90.45\% in RPR vs $89.5 \%$ in VDRL). VDRL and RPR are non-treponemal tests, in which false-negative results can be observed in patients who have been treated or are at the latent or advanced stage of syphilis, as the sensitivity of the non-treponemal tests is lower at this stage. This may explain the low VDRL/RPR sensitivity detected in this study. The same finding was observed by Naidu $e t$ al. (2012) who found that ELISA had higher sensitivity and specificity of $96 \%$ and $90 \%$, respectively, whereas RPR had 70\% and $54 \%$, respectively, with TPHA as the reference standard. ${ }^{7}$

Based on the research of Solaimalai et al. (2020), VDRL or RPR test is routinely used in many laboratories as a screening test for syphilis because of its ease of performance, sensitivity, and low cost. Their sensitivity in the primary, secondary, and tertiary stages of syphilis are $60 \%-70 \%, 100 \%$, and 60\%-70\%, respectively. The test can be performed on both serum and cerebrospinal fluid specimens and is an indicator of response to treatment in 6-18 months. ${ }^{4}$ However, the drawback of these tests is the pro-zone phenomenon $(0.8 \%-2 \%)$ which leads to false-negative reports, ${ }^{8} 18-20$ whereas $26 \%$ $56 \%$ positive VDRL/RPR tests can turn out to be biological false positives. Additionally, the VDRL is a labor-intensive manual test that requires trained personnel and can only be performed in large volume laboratories. ${ }^{9}$

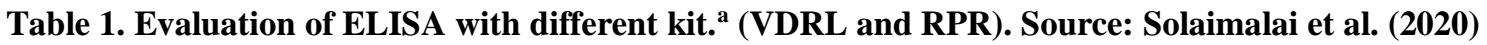

\begin{tabular}{|c|c|c|c|c|c|c|c|c|}
\hline & TPHA & & & & & & & False positive \\
\hline & Positive & Negative & Sensitivity & Specificity & PPV & NPV & Kappa & rate $(\%)$ \\
\hline $\begin{array}{l}\text { ELISA Lot No E } 171206 \text { AI } \\
\text { Positive }(n=76) \\
\text { Negative }(n=132)\end{array}$ & $\begin{array}{c}72 \\
1\end{array}$ & $\begin{array}{c}4 \\
131\end{array}$ & $\begin{array}{l}98.63 \\
(92.60-99.97)\end{array}$ & $\begin{array}{l}97.04 \\
(92.59-99.19)\end{array}$ & $\begin{array}{l}94.74 \\
(87.27-97.93)\end{array}$ & $\begin{array}{l}99.24 \\
(94.92-99.89)\end{array}$ & $\begin{array}{l}0.95 \\
(0.902-0.993)\end{array}$ & 3 \\
\hline $\begin{array}{l}\text { ELISA Lot No E } 171206 \text { AG } \\
\text { Positive }(n=53) \\
\text { Negative }(n=153)\end{array}$ & $\begin{array}{c}48 \\
3\end{array}$ & $\begin{array}{c}5 \\
150\end{array}$ & $\begin{array}{l}94.12 \\
(83.76-98.77)\end{array}$ & $\begin{array}{l}96.77 \\
(92.63-98.94)\end{array}$ & $\begin{array}{l}90.57 \\
(80.17-95.80)\end{array}$ & $\begin{array}{l}98.04 \\
(94.34-99.34)\end{array}$ & $\begin{array}{l}0.9 \\
(0.827-0.967)\end{array}$ & 3.2 \\
\hline $\begin{array}{l}\text { ELISA Lot No E } 171206 \text { AK } \\
\text { Positive }(n=73) \\
\text { Negative }(n=131)\end{array}$ & $\begin{array}{c}65 \\
3\end{array}$ & $\begin{array}{c}8 \\
128\end{array}$ & $\begin{array}{l}95.6 \\
(87.64-99.08)\end{array}$ & $\begin{array}{l}94.12 \\
(88.74-97.43)\end{array}$ & $\begin{array}{l}89.04 \\
(80.55-94.10)\end{array}$ & $\begin{array}{l}97.71 \\
(93.38-99.23)\end{array}$ & $\begin{array}{l}0.88 \\
(0.813-0.949)\end{array}$ & 5.9 \\
\hline
\end{tabular}

Abbreviations: CI, confidence interval; ELISA, enzyme-linked immunosorbent assay; FN, false negative; FP, false positive; NPV, negative predictive value; PPV, positive predictive value; TPHA, Treponema pallidum hemagglutination. aValues are given as percentage $(95 \% \mathrm{CI})$.

The recommendation of the study by Solaimalai et al. (2020) is that ELISA has the potential to replace VDRL/RPR as a syphilis screening test in centers that can perform ELISA, especially for antenatal screening in large-volume laboratories. ${ }^{4}$ However, in terms of availability of test kits and affordability for the community, ELISA is not yet potential as a screening test that can be applied in Indonesia for triple elimination screening in pregnancy. Indonesia also relies on small, distributed community health centers ("Puskesmas") which can perform 
simple screening tests for syphilis, ${ }^{10}$ and not large-volume laboratories, so that from the comparison between RPR and VDRL, RPR is the better option for screening tests.

\section{CONCLUSION}

From research conducted by Solaimalai et al. (2020), it can be concluded that VDRL is not more sensitive and specific than RPR so that RPR is better used as a diagnostic screening test for syphilis infection in pregnant women than VDRL. The research undertaken is quite complete and purposeful as a cross-sectional study. The sampling process is carried out by means of simple random sampling and the results obtained are reliable. However, this research is not necessarily applicable to countries with limited availability of diagnostic tests and the socio-economic conditions of society, such as Southeast Asian countries. Thus, further research is needed related to the comparison of the use of conventional diagnostic tests such as RPR and VDRL in these countries.

\section{ACKNOWLEDGMENT}

Authors would like to give the highest gratitude towards Dr. Pudji Lestari, dr. M. Kes., as an author and also an adviser for authors during the making of the literature review. Also, for our institution, Universitas Airlangga, for the support so that this article could be made and published. There is no conflict of interest in this literature review.

\section{REFERENCES}

1. Wu X, Hong F, Lan L, et al (2016). Poor awareness of syphilis prevention and treatment knowledge among six different populations in south China, BMC Public Health, 16(1), 1-7

2. Peeling RW. Mabey D, Kamb ML, et al (2017). Syphilis, Nat Rev Dis Primers, 3, doi: 10.1038/nrdp.2017.73
3. Landry ML, Peaper D (2017). Laboratory Updates: Clinical Virology and Microbiology. Yale New Haven Health, 26(2), 1-2

4. Solaimalai D, Rathore S, Beck MM, et al (2020). Enzyme-linked immunosorbent assay (ELISA) versus Venereal Disease Research Laboratory test (VDRL) and rapid plasma reagin test (RPR) for screening of syphilis in pregnant women. Int J Gynaecol Obstet, 150(1), 103-107

5. Curry SJ, Krist AH, Owens DK, et al (2018). Screening for Syphilis Infection in Pregnant Women: US Preventive Services Task Force Reaffirmation Recommendation Statement. JAMA, 320(9), 911-917.

6. World Health Organization (2017). WHO 2017 Syphilis in Pregnancy Guidelines. Available at: https://www. who.int/reprouctivehealth/publications /rtis/syphilis-ANC-screenandtreatguidelines/en/

7. Naidu NK, Bharucha ZS, Sonawane V, et al (2012). Comparative study of Treponemal and non-Treponemal test for screening of blood donated at a blood center. Asian J Transfus Sci, 6(1), 32-35

8. Lombardo J, Alhashim M (2018). Secondary syphilis: an atypical presentation complicated by a false negative rapid plasma reagin test. Cutis, 101(5), E11-E13

9. Schmidt BL, Edjlalipour M, Luger A (2000). Comparative evaluation of nine different enzyme-linked immunosorbent assays for determination of antibodies against Treponema pallidum in patients with primary syphilis. J Clin Microbiol, 38(3), 1279-1282

10. Baker C, Limato R, Tumbelaka $P$, et al (2020). Antenatal testing for anaemia, HIV and syphilis in Indonesia - A health systems analysis of low coverage. BMC Pregnancy and Childbirth, 20(1), 1-11 